\title{
Can confidence indicators forecast the probability of expansion in Croatia?
}

\author{
Mirjana Čižmešija ${ }^{1, *}$ and Nataša Erjavec ${ }^{1}$ \\ ${ }^{1}$ Faculty of Economics and Business, University of Zagreb \\ J. F. Kennedy 6, 10000 Zagreb, Croatia \\ E-mail: $\langle\{$ mcizmesija,nerjavec\}@efzg.hr
}

\begin{abstract}
The aim of this paper is to investigate how reliable are confidence indicators in forecasting the probability of expansion. We consider three Croatian Business Survey indicators: the Industrial Confidence Indicator (ICI), the Construction Confidence Indicator (BCI) and the Retail Trade Confidence Indicator (RTCI). The quarterly data, used in the research, covered the periods from 1999/Q1 to 2014/Q1. Empirical analysis consists of two parts. The non-parametric Bry-Boschan algorithm is used for distinguishing periods of expansion from the period of recession in the Croatian economy. Then, various nonlinear probit models were estimated. The models differ with respect to the regressors (confidence indicators) and the time lags. The positive signs of estimated parameters suggest that the probability of expansion increases with an increase in Confidence Indicators. Based on the obtained results, the conclusion is that ICI is the most powerful predictor of the probability of expansion in Croatia.
\end{abstract}

Key words: confidence indicators, expansion, business survey, probit models

Received: March 4, 2016; accepted: March 21, 2016; available online: March 31, 2016

DOI: $10.17535 /$ crorr.2016.0007

\section{Introduction}

Many researches and papers incorporate the psychological sentiment (obtained by Business and Consumer Surveys; BCS) in macroeconomic modelling [19, 11, 13, 7, 4, 21, 17]. Namely, BCS offer direct assessments of the otherwise intangible factors such as economic agents' perceptions and expectations. They measure the agents' willingness to consume/invest/save, as opposed to their ability to do the same. Hence, these psychological factors are crucial to understanding the underlying market forces and agents' behaviour. The BSC researches published so far (both for Croatia and the majority of developing countries) mostly rely on well-known econometric methods such as linear time series models, or simple regression/correlation analysis $[8,1,2,16]$. However, the

* Corresponding author. 
role of economic agents' sentiment in governing actual economic developments can be explained using probability models.

\section{Business and consumer survey - Croatian experience and literature review}

Business and consumer survey data represents certain timely economic information derived from qualitative questions asking managers and consumers about assessments and expectations on the state of the economy. To summarize managers' subjective assessment of economic variables, there are different approaches in using and interpreting business survey results as leading or coincidence indicators [7]. These indicators are used to explain and predict changes in macroeconomic variables.

Since 1995, Business surveys in Croatia have been conducted on a quarterly basis in manufacturing industry, construction and retail trade, and in the services sector since 2008. The surveys are conducted using the harmonized EU methodology, adjusted for specific characteristics of the Croatian economy. The surveys are financed by the Croatian Chamber of Commerce and carried out by the Research Centre of the business journal Privredni vjesnik, which regularly publishes the survey findings [5]. Variables as measures derived from the business surveys are expressed as a difference (balance) between weighted percentages of the positive (good) and negative (bad) responses of managers to questions.

The questions in the business surveys are (in essence) of a qualitative nature with three reply options: positive (increase, more than sufficient, etc.), equal (remain unchanged, sufficient, etc.) and negative (decrease, not sufficient, etc.). For each answer option (positive, equal or negative) relative frequencies are calculated. The common way of presenting business survey data is the balance. If $\mathrm{P}, \mathrm{E}$ and $\mathrm{M}$ denote percentages of respondents' chosen options: positive, equal and negative, respectively, with the sum equalling 100 for each variable, the balance is defined as the difference between $\mathrm{P}$ and $\mathrm{M}$ (difference between the percentages of respondent's positive and negative replies). In accordance with the Harmonized European Business Survey methodology [6], a weighted counting of answers is used in the Croatian business survey. This means that the answers of each respondent are weighted with the coefficient in line with a business's turnover. Balance (B) is calculated for all questions (variables). In general, time series of balances are seasonally adjusted and then used in calculating composite indicators. The European Commission is using Dainties as the seasonal-adjustment algorithm, as originally developed by Eurostat. The main advantage of Dainties is the absence of revision of past data when adding data at the end of a time series. Croatia's survey data are seasonally adjusted using Dainties, as well. 
In the simplest way, the time series of seasonally adjusted balances can be used as a basis for explaining and predicting changes in a national economy. The next level in aggregation of business survey data is calculating composite (confidence) indicators for the three different sectors: manufacturing industry, construction and retail trade.

Each confidence indicator is calculated as the simple arithmetic average of the seasonally adjusted balances of answers to specific questions chosen from the full set of questions in each survey. The selection of questions was guided by the aim of achieving as high as possible coincident correlation of the confidence indicator with a reference series [6], such as year-on-year growth in industrial production.

Only three variables are used in calculating the composite indicator in the manufacturing industry, i.e. the Industrial Confidence Indicator (ICI), namely: order books, stock of finished products (with an inverted sign) and production expectation. Balances are seasonally adjusted. The Construction Confidence Indicator (BCI) is the arithmetic average of seasonally adjusted balances of answers to the questions on order books and employment expectations. The Retail Trade Confidence Indicator (RTCI) is the arithmetic average of seasonally adjusted balances of answers to the questions on the present and future economic situation, and on stocks (the last with an inverted sign).

Confidence indicators effectively predict changes in the macroeconomic reference series (at national and regional level) up to six months in advance [9]. There have been many research results, studies and papers on this subject (for a list of results see: $[4,8]$. Some empirical researches have shown the existence of a relationship between business survey variables and confidence indicators with the reference series $[11,12]$.

According to research results in Croatia during the last 10 years (as in: [1, $2,16,21]$, the Croatian Industrial Confidence Indicator correctly predicts changes in Croatian industrial production one or two quarters ahead in almost $60 \%$ of cases. However, the latest results have not been so good. Moreover, Croatia's business survey indicators in construction and in retail trade have been shown to be weak predictors of national economy.

However, some researches $[14,19,5]$ indicate that in the recession period (after 2008), harmonized indicators used in an official sense, do not exhibit good predictive properties. Therefore, these indicators should be revised, new ones considered or certain methodological improvements implemented when using indicators as coincidence of leading indicators, in order to accurately predict changes in the macroeconomic reference series one or two quarters ahead. The survey research conducted in this paper is one of the methodological improvements that aims to investigate the potential forecasting property of BCS Indicators. 


\section{Business cycle turning points for Croatia}

To distinguish the periods of expansion from periods of recession in the Croatian economy, we applied the non-parametric BBQ algorithm proposed by Pagan and Harding, [17]. The BBQ algorithm is a quarterly implementation of the original Bry and Boschan, [3] BB monthly algorithm. The potential turning points are identified as the local minima (troughs) and maxima (peaks) for real seasonally adjusted quarterly GDP data. Between a peak and trough of economic activity an economy is in a contractionary phase (a recession), whereas between a trough and peak of activity an economy is in an expansionary phase (a recovery). Although the algorithm is wildly used to analyse business cycles, the drawback is that it cannot identify turning points at the beginning of a sample (the first two observations) nor at the end of a time series (the last two observations), as there are no previous or subsequent observations for these observations $[17,10]$.

Since quarterly GDP data are available for the period 1997/Q1-2014/Q1, the $\mathrm{BBQ}$ dating algorithm was applied to that period. In the analysed period, the $\mathrm{BBQ}$ algorithm identified three recession periods in Croatia's economic activity (1998/Q2-1999/Q2, 2009/Q1-2010/Q2 and 2011/Q3-2013/Q1). The post-war recession ended in the second quarter of 1999 (trough), which was followed by a long period of expansion, ending in 2008/Q4 (peak). The Croatian economy subsequently entered another recession in the first quarter of 2009, and ended in 2010/Q2. The expansion which followed lasted for almost a year. Another recession is detected for the period 2011/Q3-2013/Q1.

The algorithm detected the business cycle peak in the third quarter of 2013 indicating the end of the expansion period and beginning of another recession in the Croatian economy. The algorithm applied on the data prior to the first quarter of 2014 shows that the recession, which began in the fourth quarter of 2013, had not ended by the first quarter of 2014 .

\section{Data selection}

To separate periods of expansion from periods of recession, as a relevant measure of economic activity, quarterly data on GDP (real GDP at market prices of the previous year) are used. Data provided from Eurostat are available from the first quarter of 1997 to the first quarter of 2014, and are seasonally adjusted and adjusted for working days using the Demetra statistical software Tramo/Seats seasonal adjustment method. Data for predictor variables, i.e. the Croatian Business Survey's confidence indicators (ICI, BCI and RTCI), are taken from Privredni vjesnik and are available from the first quarter of 1999 to the first quarter of 2014. The availability of data for the business survey 
indicators limited the empirical analysis for the period from the first quarter of 1999 to the first quarter of 2014.

\section{Methodology}

The empirical analysis consists of two parts. In the first part, the variable expansion is defined based on results obtained from the BBQ algorithm. In the second part, various probit models were estimated $[18,15]$. The models differ in the predictor variable (Business Survey Indicator) and in its time lag included in the model.

In all probit models the dependent variable is a binary expansion indicator which takes a value of one to indicate that an economy is in an expansionary state at time $t$, and a value of zero, if economy is in a recession state at time $t$. Based on the predictor variable, we consider a set of Croatian Business Survey indicators such as; Industrial Confidence Indicator (ICI), Construction Confidence Indicator (BCI) and Retail Trade Confidence Indicator (RTCI). The indicators are calculated in line with the harmonized European Union methodology. The standard probit model that quantifies expansion probabilities is given by the equation (1).

$$
\mathrm{P}\left(\mathrm{Y}_{\mathrm{t}}=1\right)=\mathrm{F}\left(\mathrm{b}_{0}+\mathrm{b}_{1} \mathrm{X}_{\mathrm{t}}\right)
$$

where $\mathrm{P}\left(\mathrm{Y}_{\mathrm{t}}=1\right)$ is the probability that the economy is in expansion at time $t . \mathrm{X}_{\mathrm{t}}$ is a predictor variable. Predictor variables in the estimated models are Croatia's business survey indicators: ICI, BCI or RTCI. $b_{0}$ and $b_{1}$ are unknown parameters and $\mathrm{F}(\cdot)$ denotes the cumulative distribution function of the standard normal distribution.

The probit models generate a probability of expansion from information in a set of leading indicators. The closer the probability is to 1 , the more likely the economy will be in expansion; the closer the probability is to 0.5 the less likely the economy will be in expansion. These probabilities can be easily used to predict the turning point from expansion to recession. When the probability of expansion exceeds 0.5, the economy is more likely to be headed toward expansion than remaining in recession, and thus a business cycle turning point is signalled.

After the estimation of probit models for each predictor, the various measures are employed to discriminate between models. Model selection criteria include two types of measures; measures of model fit and measures of model classification ability. For measures of model fit, we calculated the pseudo Rsquared (pseudo R2) and the information criteria (AIC and BIC). Additionally, a Pearson goodness of fit test and Hosmer-Lemeshow goodness of fit test are performed. 
The pseudo R-squared is McFadden R-squared, known as the "likelihood ratio index", and compares a model without any predictor to a model being estimated. It is defined as one minus the ratio of the log likelihood with intercepts only, and the log likelihood for the model being estimated.

The second group of measures refers to the measures of model classification ability, such as the overall rate of correct classification and the area under the ROC curve (AUROC). The ROC curve (receiver operating characteristic curve) is a useful tool to select a possibly optimal model. It captures the ability of each model to accurately categorize recessions and expansions. The area under the ROC curve (AUROC) quantifies the overall ability of the model to discriminate between two states (in our case expansion and recession). A larger value of AUROC is preferred. The model with no predictive power has an area of 0.5 whereas the perfect model has an area of 1 .

\section{Empirical results}

Changing the predictor variable and its lag length included in the model, different probit models are estimated. Based on economic theory and empirical results $[9,16]$, it is evident that Business Survey indicators can predict changes in referent macroeconomic series instantaneously and for one or two quarters ahead. For each predictor (business survey indicator: ICI, BCI and RTCI), we analyse its instantaneous predictive performance for Croatian expansion, as well as at horizons of one and two quarters.

The estimates from models with two predictors (Industrial Confidence Indicator (ICI) and Construction Confidence Indicator (BCI)) are presented in Table 1 and Table 3. The signs of the estimated parameters in all models are positive, as expected, (Table 1 and Table 3) implying that the probability of expansion is higher as the values of indicators increase.

\begin{tabular}{|l|c|c|c|}
\hline & $\mathrm{ICI}_{\mathrm{t}}$ & $\mathrm{ICI}_{\mathrm{t}-1}$ & $\mathrm{ICI}_{\mathrm{t}-2}$ \\
\hline Parameter estimate* & 0.0867 & 0.1303 & 0.0766 \\
\hline Standard error & 0.0232 & 0.0335 & 0.0211 \\
\hline p-value, $\mathrm{P}>|\mathrm{z}|$ & $<0.0001$ & $<0.0001$ & $<0.0001$ \\
\hline \multicolumn{2}{|c|}{$*$ An estimate of a constant is not reported }
\end{tabular}

Table 1: Estimates of probit models (predictor ICI variable)

Based on the results of both chi-square goodness of fit tests (Pearson and Hosmer-Lemeshow), all models are correctly specified and cannot be rejected (Table 2 and Table 4). Additionally, the area under the ROC curve (exceeding $0.8)$ points to a high predictive power for all the estimated models. 


\begin{tabular}{|c|c|c|c|}
\hline $\begin{array}{c}\text { Measures of } \\
\text { model fit }\end{array}$ & $\mathrm{ICI}_{\mathrm{t}}$ & $\mathrm{ICI}_{\mathrm{t}-1}$ & $\mathrm{ICI}_{\mathrm{t}-2}$ \\
\hline Pseudo R2 & 0.2986 & 0.4610 & 0.2767 \\
\hline $\mathrm{AIC}$ & 54.6322 & 41.5079 & 52.3855 \\
\hline $\mathrm{BIC}$ & 58.8540 & 45.6966 & 56.5406 \\
\hline $\begin{array}{l}\text { Pearson } \\
\text { test }\end{array}$ & $\begin{array}{c}\operatorname{chi}^{2}(59)=48.11 \\
\text { Prob }>\operatorname{chi}^{2}= \\
0.8437\end{array}$ & $\begin{array}{c}\operatorname{chi}^{2}(58)=38.61 \\
\text { Prob }>\text { chi }^{2}=0.9766\end{array}$ & $\begin{array}{c}\operatorname{chi}^{2}(57)=51.10 \\
\text { Prob }>\text { chi }^{2}= \\
0.6948\end{array}$ \\
\hline $\begin{array}{l}\text { Hosmer - } \\
\text { Lemeshow } \\
\text { test }\end{array}$ & $\begin{array}{c}\operatorname{chi}^{2}(8)=10.64 \\
\text { Prob }>\operatorname{chi}^{2}= \\
0.2227\end{array}$ & $\begin{array}{c}\operatorname{chi}^{2}(8)=6.97 \\
\text { Prob }>\text { chi }^{2}=0.5403\end{array}$ & $\begin{array}{c}\operatorname{chi}^{2}(8)=4.81 \\
\text { Prob }>\operatorname{chi}^{2}= \\
0.7778\end{array}$ \\
\hline \multicolumn{4}{|c|}{ Measures of model classification ability } \\
\hline $\begin{array}{l}\text { Correctly } \\
\text { classified }\end{array}$ & $77.05 \%$ & $85.00 \%$ & $79.66 \%$ \\
\hline $\begin{array}{ll}\text { Area } & \text { under } \\
\text { the } & \text { ROC } \\
\text { curve } & \end{array}$ & 0.8676 & 0.9261 & 0.8621 \\
\hline
\end{tabular}

Table 2: Measures of model fit (predictor ICI variable)

The overall model selection evidence (Table 2) indicates that the model with a one quarter lag of ICI is superior to other models. The overall rate of correct classification for that model is estimated to be $85 \%$. The value of the ICI indicator in the previous quarter is a strongly statistically significant predictor of expansion period in Croatia. The obtained results confirm the conclusions drawn from previous researches, i.e. on the basis of changes in ICI, changes in the whole national economy can be correctly predicted with a one quarter lag.

\begin{tabular}{|l|c|c|c|}
\hline & $\mathrm{BCI}_{\mathrm{t}}$ & $\mathrm{BCI}_{\mathrm{t}-1}$ & $\mathrm{BCI}_{\mathrm{t}-2}$ \\
\hline Parameter estimate & 0.0345 & 0.0284 & 0.0185 \\
\hline Standard error & 0.0093 & 0.0082 & 0.0070 \\
\hline $\mathrm{p}$-value, $\mathrm{P}>|\mathrm{z}|$ & $<0.0001$ & 0.0010 & 0.0080 \\
\hline
\end{tabular} An estimate of a constant is not reported

Table 3: Estimates from the probit models (predictor BCI variable)

In analysing the relative model performance with the BCI indicator as a predictor variable (Table 4), the appropriate model appears to be a model without lag (instantaneous impact of BCI indicator). However, measures of model fit and measures of model classification ability may lead to different conclusions.

The values of parameter estimates in all models (Table 3) are positive and decrease with an increase in a time lag of BCI. The highest value is obtained in the model without a lagged predictor. If we know that business survey results are available approximately one quarter before the publishing of official 
statistical GDP data, BCI can be used to predict changes in a national economy and in signalising expansion.

\begin{tabular}{|c|c|c|c|}
\hline $\begin{array}{c}\text { Measures of } \\
\text { model fit }\end{array}$ & $\mathrm{BCI}_{\mathrm{t}}$ & $\overline{B C I} I_{t-1}$ & $\mathrm{BCI}_{\mathrm{t}-2}$ \\
\hline Pseudo R2 & 0.2820 & 0.2244 & 0.1152 \\
\hline AIC & 55.8324 & 57.97373 & 63.1907 \\
\hline BIC & 60.0542 & 62.1624 & 67.3458 \\
\hline $\begin{array}{l}\text { Pearson } \\
\text { test }\end{array}$ & $\begin{array}{c}\operatorname{chi}^{2}(59)=46.51 \\
\text { Prob }>\text { chi }^{2}= \\
0.8809\end{array}$ & $\begin{array}{c}\operatorname{chi}^{2}(58)=58.38 \\
\text { Prob }>\text { chi }^{2}= \\
0.4615\end{array}$ & $\begin{array}{c}\operatorname{chi}^{2}(57)=61.12 \\
\text { Prob }>\operatorname{chi}^{2}= \\
0.3303\end{array}$ \\
\hline $\begin{array}{l}\text { Hosmer- } \\
\text { Lemeshow } \\
\text { test }\end{array}$ & $\begin{array}{c}\text { chi }^{2}(8)=5.59 \\
\text { Prob }>\text { chi }^{2}= \\
0.6933\end{array}$ & $\begin{array}{c}\operatorname{chi}^{2}(8)=6.41 \\
\operatorname{Prob}^{>} \mathrm{chi}^{2}= \\
0.6017\end{array}$ & $\begin{array}{c}\operatorname{chi}^{2}(8)=10.30 \\
\operatorname{Prob}^{>} \mathrm{chi}^{2}= \\
0.2443\end{array}$ \\
\hline \multicolumn{4}{|c|}{ Measures of model classification ability } \\
\hline $\begin{array}{l}\text { Correctly } \\
\text { classified }\end{array}$ & $73.77 \%$ & $75.00 \%$ & $74.58 \%$ \\
\hline $\begin{array}{l}\text { Area under } \\
\text { the ROC } \\
\text { curve }\end{array}$ & 0.8275 & 0.8139 & 0.7364 \\
\hline
\end{tabular}

Table 4: Measures of model fit (predictor BCI variable)

The Retail Trade Confidence Indicator (RTCI) proved to be an insignificant predictor of Croatian expansion in all models (regardless of the lag length). The estimated parameters in all models were statistically insignificant as can be seen in Table 5 .

\begin{tabular}{|l|c|c|c|}
\hline & $\mathrm{RTCI}_{\mathrm{t}}$ & $\mathrm{RTCI}_{\mathrm{t}-1}$ & $\mathrm{RTCI}_{\mathrm{t}-2}$ \\
\hline Parameter estimate* & 0.0054 & -0.0055 & -0.0113 \\
\hline Standard error & 0.0093 & 0.0138 & 0.0114 \\
\hline p-value, $\mathrm{P}>|\mathrm{z}|$ & 0.562 & 0.594 & 0.325 \\
\hline \multicolumn{2}{|c}{} \\
* An estimate of a constant is not reported
\end{tabular}

Table 5: Estimates from the probit models (predictor RTCI variable) 


\section{Conclusions}

This paper examines the performance of various probit models in forecasting the probability of expansion in Croatia based on a set of Croatian Business Survey indicators such as the Industrial Confidence Indicator (ICI), the Construction Confidence Indicator (BCI) and the Retail Trade Confidence Indicator (RTCI). Nonlinear probit models applied in this paper are a methodological improvement for examining and explaining predictive properties of Croatian Business survey indicators. In accordance with well-known theoretical and empirical findings, the probit models were estimated for the business survey indicators instantaneously (without lags) and for one or two quarters of lag.

In predicting the direction of changes in industrial production and in an entire national economy, ICI proved to have the best predictive abilities with a one quarter lead. That means that an increase of one point in ICI in a current quarter, signals an increase of economic activity in the next quarter. Our research results based on the new methodological basis has confirmed this conclusion. The highest (positive) value of the estimated parameter is obtained in the probit model with ICI predictor with a one quarter lead (in that case, all measures of model fit are optimal).

Following the evidence obtained in our study, the BCI has been found to be a useful predictor variable for the Croatian expansion period as well. Ambiguous conclusions can be derived on the basis of measures of model fit and measures of model classification ability. Values of estimated parameters in all probit models are positive, thus indicating a positive relationship between the indicator and the probability that the economy is in expansion. The highest value of the estimate is obtained for the model without lag, i.e. for the model with instantaneous impact of the BCI indicator. It shows that BCI is a coincidence (not leading) indicator. Since the business survey results are available approximately one quarter before the publishing of official statistical GDP data, our results show that BCI can (nevertheless) be used as a leading indicator of change in the national economy.

The Retail Trade Confidence Indicator (RTCI) proved to be an insignificant predictor of Croatian expansion in all models (regardless of the lag length of a predictor included in the model).

Research on the Croatian business cycle relies mostly on Business and Consumer Surveys (BCS). The recent global financial crisis has opened a variety of economic fields which could greatly benefit from BCS results. Namely, the BCS offer a direct empirical assessment of otherwise "intangible" factors, such as economic agents' perceptions and expectations. Nonlinear probit models applied in this paper are one of the methodological improvements in explaining BCS results in short-term macroeconomic forecasting. However, apart from Croatia, it would be interesting to analyse and compare (using the nonlinear 
probit methodology applied in paper) the forecast properties of BCS indicators for countries that recently joined the EU.

\section{Acknowledgement}

This work has been fully supported by the Croatian Science Foundation under the project No. 3858 .

Some of the survey results published in the paper were presented at "The second International Conference on Business Management and Economics (ICBME) 2016", Colombo (Sri Lanka) 19-20 February 2016.

\section{References}

[1] Bahovec, V., Čižmešija, M. and Kurnoga Živadinović, N. (2006). The forecasts of some macroeconomic variables for Croatia using the information provided by business surveys. Proceedings of the 11th International Conference on Operational Research KOI 2006, Boljunčić, V. (editor), Pula, Croatia, September 27-29, 2006, $77-86$.

[2] Bahovec, V., Čižmešija, M. and Kurnoga Živadinović, N. (2007). Testing for granger causality between economic sentiment indicator and gross domestic product for the Croatian economy. Proceedings of the 9th International Symposium on Operational Research SOR '07, Zadnik Stirn, N., Drobne, S. (editors), Nova Gorica, Slovenia, September 26-28, 2007, 403-408.

[3] Bry, G. and Boschan, C. (1971). Cyclical Analysis of Time Series: Selected Procedures and Computer Programs. NBER, New York.

[4] Claveria, O., Pons, E. and Ramos, R. (2005). Business and consumer expectations and macroeconomic forecasts. Proceedings of Conference on Survey data in Economics - Methodology and Applications, Cess IFO, Munich, 1-20.

[5] Čižmešija, M., Erjavec, N. and Bahovec, V. (2014). The role of business survey measures in forecasting Croatian industrial production. International Journal of Social, Human Science and Engineering, 8, 3, 67-72.

[6] European Commission, (2014). The joint harmonized EU programme of business and consumer surveys. User guide, European Economy, Directorate-General for Economic and financial affairs.

[7] Frale, C., Marcellino, M., Mazzi, G. L. and Proietti, T. (2009). Survey data as coincidence and leading indicators. European University Institute Working Paper ECO 2009/19, Florence.

[8] Fusari, A and Pellissier, M. (2008). Some new indicators and procedures to get additional information from the Business Tendency Surveys. Proceedings of the 29th CIRET Conference, Santiago.

[9] Gayer, C. (2004). Forecast evaluation of European commission survey indicators. Proceedings of the 27th CIRET Conference, Warsaw.

[10] Krznar, I. (2011). Identifying recession and expansion periods in Croatia. Working Papers W-29, Croatian National Bank. Zagreb. 
[11] Kurnoga, N., Erjavec, N. and Bahovec, V. (2015). The analysis of association between the variables in Croatian business survey for services sector. The Business \& Management Review, Datta, P. R. (editor), 263-268.

[12] Kurnoga, N. and Čižmešija, M. (2015). Has the long-term recession changed managers' assessments and expectations in the Croatia's retail trade sector? Proceedings of the 13th International Symposium on Operational Research SOR '15, Zadnik Stirn, L., Žerovnik, J., Kljajić Borštnar, M., Drobne, S. (editor.), Ljubljana: Slovenian Society Informatika, Section for Operational Research, 508-513.

[13] Liu, W. and Moench, E. (2014). What Predicts U.S. Recessions? Federal Reserve Bank of New York, Staff Report, No. 691.

[14] Lolić, I., Sorić, P. and Čižmešija, M. (2015). Redefining the Croatian economic sentiment indicator. International Journal of Social, Behavioural, Education, Economic and Management Engineering, 9(8), 2337-2340

[15] Long, J. S. and Freese, J. (2014). Regression Models for Categorical Dependent Variables Using Stata. 3rd ed. New York. College Station, TX Stata Press.

[16] Nikić, G., Šošić, I. and Čižmešija, M. (2002). Business and investment surveys in Croatia - a case study of an economy in transition. Proceedings (CD) 26th CIRET Conference in Taipei, 16-19, October 2002, 12.

[17] Pagan, A. and Harding, D. (2002). Dissecting the cycle: A methodological investigation. Journal of Monetary Economics, 49, 2, 365-381.

[18] Powers, D. A., and Xie, Y. (2008). Statistical Methods for Categorical Data Analysis. 2nd ed. Bingley. Emerald.

[19] Sorić, P. and Čižmešija, M. (2015). Economic sentiment and the recession depth in Croatia: A structural break analysis. The Business \& Management Review, Datta P. R. (editor), New York: The Academy of Business \& Retail Management, 192-200.

[20] Sorić, P. (2013). Assessing the sensitivity of consumption expenditure to inflation sentiment in post-communist economies, Post-Communist Economies, 15/4, 529538.

[21] Šošić, I. and Čižmešija, M. (2003). A note about forecasting accuracy of business survey in Croatia. Bulletin of the International Statistical Institute, 54th Session, Contributed Papers, Vol. LX, Book 2, 465-466. 